\title{
The influence of a 12-week program of physical activity on changes in body composition and lipid and carbohydrate status in postmenopausal women
}

\author{
Wanda Barbara Pilch ${ }^{1}$, Dariusz Mikołaj Mucha², Tomasz Adam Pałka ${ }^{3}$, Agnieszka Ewa Suder ${ }^{1}$, \\ Anna Małgorzata Piotrowska ${ }^{1}$, Anna Katarzyna Tyka ${ }^{4}$, tukasz Marcin Tota ${ }^{3}$, Tadeusz Ambroży ${ }^{2}$ \\ ${ }^{1}$ Department of Physiotherapy, University of Physical Education, Cracow, Poland \\ ${ }^{2}$ Department of Physical Education and Sports, University of Physical Education, Cracow, Poland \\ ${ }^{3}$ Department of Physiology and Biochemistry, University of Physical Education, Cracow, Poland \\ ${ }^{4}$ Department of Tourism and Leisure, University of Physical Education, Cracow, Poland
}

\begin{abstract}
Introduction: For years there have been studies on what kind of physical activity is optimal for maintaining proper health condition. Besides well known and approved endurance training of moderate intensity, an importance of interval exercise where short term, sudden intensification of work is performed at low endurance load is emphasized. The aim of the work was to assess the effects of a program of physical activity applied to postmenopausal women regarding improvement of their body composition and biochemical indices of lipid and carbohydrate status.

Material and methods: The program of physical activity contained 12-week trainings of Nordic walking (NW) and gymnastic-dance classes (G-D). The intensity of effort during the NW training was at the level of $60 \%$ $\mathrm{HR}_{\max }$, whereas intensity of G-D exercises was selected based on a subjective assessment of effort according to the scale of American College of Sports Medicine.

Results: The 12-week program of physical activity resulted in statistically significant lowering of total cholesterol and low density lipoprotein (LDL) fraction levels. An increase in high density lipoprotein (HDL) cholesterol level was observed, whereas the values of triacylglycerols (TG) did not change. The average fasting blood glucose level decreased significantly. Similar changes were noted for the insulin level. The analysed body biometrical-structural indices did not change significantly.

Conclusions: The applied 12-week program of physical activity without changes of dietary habits contributed to an improvement in plasma lipid profile and an increased insulin sensitivity, but it did not affect significantly body composition.
\end{abstract}

Key words: Nordic walking, HDL, LDL, insulin sensitivity.

\section{Introduction}

Among aetiological factors of the most frequent civilization diseases, such as atherosclerosis, cardiovascular disease, diabetes, osteoporosis or tumours, there is also a decrease in physical activity being a simple consequence of civilization development [1]. These diseases lead to an increased disability of the society (elimination from professional activity) and a growing number of deaths. The World Health Organisation (WHO) determined the following risk factors for these diseases: lack of physical activity, arterial hypertension, hyperglycaemia, lipid disorders, overweight, obesity and smoking [1]. In Poland, during the past ten years a few large scale studies were undertaken, such as NATPOL PLUS, WOBASZ which assessed the prevalence of lipid disorders in adults [2-5].
The increase in physical activity has an extensive positive influence on the state of health, which is connected with facilitation of some organs and systems activities resulting from developing post-training changes. It also positively affects metabolism by maintaining energy balance and thus lowering body weight. Growth of muscle and bone mass is an additional benefit of the increased physical activity. Physical exercise reduces the adipose tissue, improves the lipid profile and glycaemic one as well as endothelium functions, increases the activity of the immunological system and decreases oxidative stress in the organism [6].

The mechanism of the beneficial action of physical exercise on fat and carbohydrate metabolism is not fully known. Post-exercise changes in the lipid profile are connected with an improvement of insulin sensitivity 
by increased use of fatty acids as energy carriers. Physical exercise leads to an increased transport of glucose to the muscles through GLUT-4 proteins by intensification of their expression and biosynthesis and increased sensitivity to insulin. It inhibits the release of fatty acids, decreases synthesis and release of triacylglycerols in the liver, lowers the concentration of glucose in the blood and also decreases the level of proteins carrying esters of cholesterol (CEPT) [7]. In physically active people, significantly lower levels of total cholesterol (TC) and low density lipoprotein (LDL) as well as a higher level of high density lipoprotein (HDL) fraction can be observed in comparison to sedentary people [8]. The influence of physical exercise on the lipid profile depends on its intensity and duration, and also on the sex of the participants. The best exercise causing an increase in fats metabolism is a long-term effort (aerobic one) of slight intensity (up to $70 \%$ of maximum frequency of cardiac contractions) for 2.5-5 hours weekly. Exercise of this type is recommended in healthful training [9]. The kind of activity should be adjusted to the capabilities and preferences of the training person. It can include marching, endurance marching, cycling, swimming or dancing. Endurance training should be supplemented with resistance exercises (10-15\% of the training volume). It is vital to start the exercises with a 5-10 minutes' - warm-up and finish it with cool-down exercises $[10,11]$.

Although it is known that physical activity positively affects health, studies have been conducted for years on what kind of physical activity is the most beneficial to maintain it. It is usually believed that endurance trainings of moderate intensity are the best to promote health and prevent the risk of civilization diseases. Recently, it has been found that also other forms of physical activity can be significant in health promotion. It was observed that interval exercise with short-term, sudden intensification of effort performed at low endurance workload can be beneficial for health [12]. However, expanding recommendations of applying this form of training for elderly people burdened with illnesses requires further investigations. Promotional programs of physical activity need to be modified in many cases in order to better adapt them to current capabilities of the training person.

The aim of the work was to assess the efficiency of postmenopausal women's physical activity program regarding possible improvements of their body composition and biochemical indices indicating lipid and carbohydrate status connected with health state.

\section{Material and methods}

\section{Subjects}

The tests were carried out on 42 females aged 65.24 \pm 6.77 years who attended the University of the Third
Age (Uniwersytet Trzeciego Wieku) at the Podhale State Higher Vocational School (Podhalańska Państwowa Szkoła Zawodowa) in Nowy Targ. Participation in the test was not compulsory. The volunteers had to meet the qualification criteria shown in graph no. 1 and fill in the survey form of IPAQ (International Physical Activity Questionnaire) - shortened version [13] concerning former and current physical activity. From the group of 80 applicants, 42 women who met the requirements have been selected.

According to the Helsinki Declaration ethic principles, the participants were informed about the aim and methodology of the tests and the possibility of resigning from the tests at any stage and they submitted written consent. The project received a positive opinion from the Bioethical Commission at PPWSZ in Nowy Targ No. $1 / 2013$.

\section{Program of physical activity}

The program of physical activity included 12-week trainings of Nordic walking (NW) and gymnastic-dance classes (G-D).

For 12 weeks the subjects took part in 90 min training sessions of NW once a week supervised by an instructor. Each NW training started with a warm-up and finished with stretching exercises. The intensity of effort during the NW training was at a level of $60 \%$ of $\mathrm{HR}_{\max }$ ( $H R$ was registered telemetrically with the use of cardio monitors Polar Vantage NV and Polar 610S manufactured by Polar Electro). Maximal values of the heart rate $\left(H R_{\text {max }}\right)$ were estimated routinely following the formula: $\mathrm{HR}_{\max }=220$ - age (in years) [14]. The subjects also participated in 45-min-long G-D once a week supervised by an instructor. The classes started with a warm-up followed by the main part: learning steps and choreography and exercises strengthening individual groups of muscles in medium and low positions. At the end of the classes, static stretching exercises were done. The intensity of exercises was selected based on a subjective assessment of effort according to a 20-degree scale of work heaviness for elderly people [15]. The initial part of the G-D classes lasting 15 min was assessed using the scale at 13-14 points, the main 15-min-part at 14-15 points and the final part was at 13-14 points.

\section{Examination of body composition}

Before the beginning of the program of physical activity and after it was completed, the participants underwent an examination of their body composition applying the bioelectrical impedance method (BIA) with the use of a body composition analyser (Tanita BC-601 Japan). In order to ensure the reliability of the measurements the subjects were recommended to have a bowel movement 
within 30 min before the measurement, and also not to consume alcoholic beverages for $48 \mathrm{hrs}$ and meals for 4 hrs before the tests. During the body composition analysis, the subjects were dressed in light clothes.

During the examination, body weight (BW), body height $(\mathrm{BH})$, percentage content of adipose tissue (PF\%) and fat content in kilograms (fat mass - FM), fat free body mass (lean body mass - LBM) and body mass index (BMI) have been determined.

\section{Blood sampling and biochemical tests}

One day before the beginning of the program and one day after it was completed a laboratory diagnostician collected blood samples from all the subjects on an empty stomach. They were taken from a vein in the cubital fossa in the Analytical Laboratory in Nowy Targ according to current standards. In the plasma concentrations of TC, HDL fraction of cholesterol (HDL-C), triacylglycerols (TG), glucose (G) and insulin (I) have been determined.

Total cholesterol was determined with the cholesterol test (Abbot Laboratories) dedicated for quantitative determination of cholesterol in human plasma with the enzymatic method using the Architect ci8200 analyser (Abbot Laboratories). High density lipoprotein was determined with the Ultra HDL (UHDL) test (Abbot Laboratories) used for quantitative measurement of $\mathrm{HDL}$ in human plasma with Architect ci8200 analyser (Abbot Laboratories). Low density lipoprotein fraction cholesterol was calculated using the Friedewald formula [16]:

$$
\begin{gathered}
\operatorname{LDL}-\mathrm{C}\left[\mathrm{mmol} \times \mathrm{l}^{-1}\right]=\mathrm{TC}\left[\mathrm{mmol} \times \mathrm{l}^{-1}\right]-\mathrm{TG}\left[\mathrm{mmol} \times \mathrm{I}^{-1}\right] / \\
2.2-\mathrm{HDL}\left[\mathrm{mmol} \times \mathrm{l}^{-1}\right]
\end{gathered}
$$

where: $L D L-C$ - low density lipoprotein fraction cholesterol, TC - total cholesterol, TG - triacylglycerols; LDL-C was calculated assuming that concentration of $T G$ is below $4.6 \mathrm{mmol} \times \mathrm{I}^{-1}$.

Triacylglycerols were determined with the Triglyceride test (Abbott Laboratories) used for quantitative determination of triglycerides in human plasma on the Architect ci8200 analyser (Abbot Laboratories).

The $\mathrm{HOMA}_{\mathbb{R}}$ index was calculated using the formula:

$$
\mathrm{HOMA}_{\mathrm{IR}}=\operatorname{insulin}(\mathrm{mU} / \mathrm{ml}) \times \text { glucose } \times \mathrm{mmol} / \mathrm{l} / 22.5
$$

Atherogenicity index of plasma lipoproteins (API) was calculated using the formula [17]:

$$
A P I=\log (T G / H D L-C)
$$

Atherosclerosis risk index (WRM) was calculated using the formula [18]:

$$
\text { WRM }=\mathrm{TG} / \mathrm{HDL}-\mathrm{C}
$$

\section{Analysis of nutrition}

In order to define the amount and type of food consumed daily, each of the participants kept a nutrition diary for 7 days before the beginning of trainings and during the last $12^{\text {th }}$ week of the training. On the basis of the collected data, a mean level of consumed products regarding energy value and content of proteins, fats and carbohydrates was calculated. The calculations were conducted with the use of a computer program Wikt 1.3 (IŻiż in Warsaw) and Tables of foodstuffs nutritive value $[19,20]$.

\section{Statistical methods}

Statistical analysis of the results was done with the use of the Statistica 10.0 pack for Windows by StatSoft. Conformity of variables distribution with normal distribution was checked applying the Shapiro-Wilk test. The analysis of variance with repetitive measurements (ANOVA) was used for calculations for all variables of normal distribution. All results were presented in the form of mean arithmetic values $(\bar{x}) \pm$ standard deviation (SD).

\section{Results}

The average concentration of TC tested before the beginning of trainings amounted to $6.02 \pm 1.43 \mathrm{mmol} / \mathrm{l}$ and exceeded the norm. After the program of physical activity it significantly decreased $(p<0.001)$, but was still above the norm for women. The average concentration of $\mathrm{HDL}-\mathrm{C}$ before the program was $1.39 \pm 0.37 \mathrm{mmol} / \mathrm{l}$ and was within the accepted norm limits (> $1.2 \mathrm{mmol} / \mathrm{l})$ whereas after the training it increased remarkably ( $p<0.001)$. The average concentration of LDL-C before trainings was $3.94 \pm 1.32 \mathrm{mmol} / \mathrm{l}$ being beyond the norm ( $<3.0 \mathrm{mmol} / \mathrm{l})$ accepted for women. After the trainings it significantly fell down $(p<0.001)$, but still remained above the norm. An average concentration of triglycerides before the trainings was $1.55 \pm 0.67 \mathrm{mmol} / \mathrm{l}$, which did not exceed the norm $(<1.7 \mathrm{mmol} / \mathrm{l})$ and after the training it did not change significantly. The average concentration of glucose determined after a fasting period before the trainings was $5.19 \pm 0.83 \mathrm{mmol} / \mathrm{l}$ remaining within the norm limits (3.9-5.5 mmol/l). After completing the trainings it significantly decreased $(p<0.001)$. An average concentration of insulin before the trainings was $8.15 \pm 3.93 \mathrm{mU} / \mathrm{ml}$ not exceeding the norm 6-20 $\mathrm{mU} / \mathrm{l}$. After the 12 weeks of training it decreased remarkably $(p<0.001)$. Before the trainings the insulin resistance index $\left(\mathrm{HOMA}_{\mathrm{IR}}\right)$ did not exceed the cut-off point at a value level of 2.5. After trainings it significantly decreased $(p<0.001)$. The atherogenicity index of plasma lipoproteins (API) and the atherosclerosis risk index (WRM) did not change significantly under the influence of conducted physical trainings (Table I). 
Table II presents changes in body biometrical indices of the subjects. All body biometric-structural indices did not change significantly after the 12-week-long physical training.

According to commonly accepted norms, the percentage of fat (PF) in women (22\%) is remarkably higher than in men (16\%). It is believed that a percentage content of fat in women within the range of $28-30 \%$ indicates overweight. Results at a level of $35 \%$ mean obesity. Up to $40 \%$ it is a moderate obesity and a level between $40 \%$ and $60 \%$ means a high degree obesity. It is also reflected in the Quetelet index (BMI) where expected values for women are 21-23. Overweight is 25-30 and obesity above $30 \mathrm{~kg} / \mathrm{m}^{2}$.

Although statistically insignificant changes of morphological body structure indices were observed within the examined group, it should be emphasized that they were in a proper direction. Body mass index got lower in the examined women $(\Delta \mathrm{BMI}=0.33)$, yet it still indicated overweight, both before and after the trainings (28.22 and 28.55, respectively). The percentage fat content was $30.52 \%$ before and $29.87 \%$ after, which indicates the occurrence of overweight in the exam- ined women. It should be mentioned that an increase in body weight $(\triangle \mathrm{BW}=0.8 \mathrm{~kg})$ was accompanied by an increase of lean body mass $(\triangle \mathrm{LBM}=1.01 \mathrm{~kg})$.

Table III shows components of the diet before the trainings and during the last week of physical activity. An analysis demonstrated that energy value of the diet before the trainings exceeded the norm of $1850 \mathrm{kcal} /$ day accepted for women aged 51-65 years of the lowest physical activity $(P A L=1.4)[20]$. In the last week of the training the diet energy value rose and still exceeded the acceptable norm for women of increased physical activity (PAL $=1.6)$ amounting at $2100 \mathrm{kcal} /$ day [20]. The norm of recommended protein consumption: 41-72 g/person/day [20] was exceeded in the examined women both before and after the program. Recommendations for fats intake at $57 \mathrm{~g} /$ day, if they are $30 \%$ of a diet caloric value for people of low physical activity $(P A L=1.4)$ were also above the norm in both analysed groups. An analysis of carbohydrates consumption by the examined also showed consumption above the recommended norm of $130 \mathrm{~g} /$ day [20]. Significantly higher $(p<0.05)$ values were observed in components of the analysed diet (proteins, fats) in the last week of the training.

Tab. I. Changes of selected indices of the lipid and carbohydrate profile before and after the program of physical activity in the examined women

\begin{tabular}{|c|c|c|c|c|}
\hline Index & Examination before & Examination after & $\Delta$ & $p<$ \\
\hline $\mathrm{TC}[\mathrm{mmol} / \mathrm{l}]$ & $6.02 \pm 1.43$ & $5.70 \pm 1.17$ & 0.32 & 0.001 \\
\hline $\mathrm{HDL}-\mathrm{C}[\mathrm{mmol} / \mathrm{l}]$ & $1.39 \pm 0.37$ & $1.46 \pm 0.30$ & 0.07 & 0.001 \\
\hline LDL-C [mmol/l] & $3.94 \pm 1.32$ & $3.57 \pm 1.09$ & 0.37 & 0.001 \\
\hline $\mathrm{TG}[\mathrm{mmol} / \mathrm{l}]$ & $1.55 \pm 0.67$ & $1.51 \pm 0.49$ & 0.04 & N.S. \\
\hline $\mathrm{G}[\mathrm{mmol} / \mathrm{l}]$ & $5.19 \pm 0.83$ & $5.01 \pm 0.72$ & 0.18 & N.S. \\
\hline $\mathrm{I}[\mathrm{mU} / \mathrm{ml}]$ & $8.15 \pm 3.93$ & $5.94 \pm 2.28$ & 2.21 & 0.001 \\
\hline $\mathrm{HOMA}_{\mathrm{IR}}$ & $1.96 \pm 1.31$ & $1.37 \pm 0.88$ & 0.59 & 0.001 \\
\hline AIP & $0.02 \pm 0.26$ & $0.00 \pm 0.19$ & 0.02 & N.S. \\
\hline WRM & $2.84 \pm 1.86$ & $2.50 \pm 1.16$ & 0.34 & N.S. \\
\hline
\end{tabular}

Tab. II. Changes of body biometrical-structural indices after the program of physical activity in the examined women

\begin{tabular}{lccll}
\hline Index & Examination before & Examination after & $\Delta$ & $p<$ \\
\hline BH $[\mathrm{cm}]$ & $157.92 \pm 4.93$ & $157.92 \pm 4.93$ & 0.00 & N.S. \\
\hline BM $[\mathrm{kg}]$ & $70.40 \pm 12.51$ & $71.20 \pm 12.56$ & 0.80 & N.S. \\
\hline $\mathrm{BMI}$ & $28.22 \pm 5.00$ & $28.55 \pm 6.62$ & 0.33 & N.S. \\
\hline $\mathrm{PF}[\%]$ & $30.52 \pm 5.73$ & $29.87 \pm 5.61$ & 0.65 & N.S. \\
\hline FM $[\mathrm{kg}]$ & $21.48 \pm 8.38$ & $21.27 \pm 9.07$ & 0.21 & N.S. \\
\hline LBM $[\mathrm{kg}]$ & $48.92 \pm 4.81$ & $49.93 \pm 8.60$ & 1.01 & N.S. \\
\hline
\end{tabular}

$\mathrm{BH}$ - body height, BM - body mass, BMI - body mass index, PF - percentage of fat, FM - fat mass, LBM - lean body mass, N.S. - statistical significance not found 
Tab. III. Components of a diet consumed by the participants before the trainings and during the last week of the program (mean values/person/day)

\begin{tabular}{lcccc}
\hline Components of diet & Before the training & At the end of the training & $\Delta$ & $p<$ \\
\hline Energy [kcal] & $2047.34 \pm 336.19$ & $2326.44 \pm 308.15$ & 279.1 & 0.05 \\
\hline Protein [g] & $86.1 \pm 8.02$ & $95.4 \pm 11.96$ & 9.3 & 0.05 \\
\hline Fats [g] & $70.5 \pm 27.22$ & $95.16 \pm 29.12$ & 24.66 & 0.05 \\
\hline Carbohydrates [g] & $267.11 \pm 61.11$ & $272.1 \pm 61.94$ & 4.99 & N.S. \\
\hline N.S. - statistical significance not found & & &
\end{tabular}

\section{Discussion}

Many systems and organs of the human body are affected by changes with age. Getting older is accompanied by an increase in adipose tissue content (FM) and a decrease in percentage lean body mass (LBM) which is connected mainly with the reduction in muscle proteins [21]. The loss of muscle mass can reach up to $16 \%$ during 10 years. More significant body weight changes are observed at the age of 50 , and then a significant lowering of LBM takes place [22]. After 65 there is a negative relation between body weight and LBM. The higher body weight, the lower percentage is constituted by fat free tissues. In elderly people fat distribution in the organism changes and its content grows in the trunk region and decreases in the extremities [23]. Body mass is sensitive to physical exercise. Beneficial changes connected with physical activity occur in composition of the body, therefore in its density. The influence of physical activity on the content of adipose tissue in the organism is also undeniable: people of lower physical activity have more fat tissue, regardless of age $[24,25]$. The fact that regular marching with sticks can contribute to lowering body weight and fat reserves in the organism has been confirmed by several scientific studies [26-28]. In non-obese, middle-aged women and men practising regular marches for 15 weeks (50 min/ session, 4 sessions/week) with the intensity at $65-75 \%$ $\mathrm{VO}_{2}$ max, a significant decrease in body weight, $\mathrm{BMI}$ and percentage fat content in the organism was observed [29].

In the examined women both BMI and percentage fat content in the organism indicated overweight which did not change after the training period. The 12-week training did not cause any change in body composition, which probably resulted from an improperly balanced diet and possible consumption of snacks between main meals registered during the nutrition analysis. Also the number of NW trainings that mainly are efforts when primarily fatty acids get burnt as the source of ATP to the muscles could be too low. An important element of lowering the content of adipose tissue in the organism at increased physical activity is a negative energy balance. Therefore, properly selected low caloric diet seems to be essential to cause a decrease in fat tissue content (which was not achieved in the present study).
Elimination of energy excess delivered by too high consumption of cholesterol and carbohydrates of a high glycaemic index (IG) from the diet as well as an increased physical activity lead to decreasing obesity and insulin resistance, apart from changes in the body composition. It is recommended to lower the energy intake by $500-1000 \mathrm{kcal} /$ day and increase consumption of carbohydrates containing vegetables and fruit to at least $400 \mathrm{~g} /$ day [30]. Participants of the discussed study did not change radically their dietary habits and assessment of their diet did not reveal basic nutritional mistakes. Increased energy expenditure resulting from the training participation probably was offset by increased supply of energy in the diet (statistically significant increase in the supply of fats and proteins).

After the 12-week program of physical activity some positive changes in the plasma lipid profile were observed in the examined women as well as positive changes in carbohydrate metabolism in the organism. Age is one of the risk factors for lipid disorders. Results of many studies show that an improper level of lipids in the blood occurs mainly in people with too high content of adipose tissue which is connected with lack of physical activity and wrong diet [31-35]. In the examined group the mean concentrations of TC and LDL-C were beyond referential values and indicated lipid disorders in these women.

An improper lipid profile in the blood favouring development of atherosclerosis and cardiovascular diseases is characterised by an increased content of LDL-C, TC and TG. Lowered concentration of HDL-C is an independent and inversely correlated with the prevalence of the cardiovascular system diseases risk factor [36]. In this case it is vital to find physical methods, such as properly selected physical exercises to lower the LDL-C and increase that of HDL-C which is responsible for, socalled, reverse cholesterol transport carrying excess of free cholesterol from peripheral and adipose tissues mainly to the liver [37]. An important, anti-atherosclerotic role of $\mathrm{HDL}-\mathrm{C}$ is also in preventing oxidative modification of LDL-C being an initial trigger of atherosclerotic plaque formation, and also its action on blood vessels epithelium which improves its functions by stimulation of nitric oxide production and inhibition of endothelial cells apoptosis [38-41]. Branth et al. in their studies on 
a group of middle-aged training men did not observe changes in the lipid profile in those subjects whose energy expenditure connected with the exercise was balanced by an increased energy intake [42]. In women examined by us, similarly to the men tested by Branth et al., an increased energy intake was observed during the 12-week training, which could have resulted in a lack of favourable changes in their plasma lipids profile.

One of the reasons for the increased prevalence of disorders concerning carbohydrate metabolism with increasing age is insulin resistance caused mainly by the accumulation of abdominal adipose tissue and decreased physical activity. In elderly people, as a result of higher insulin resistance, lowering of cellular glucose uptake and its metabolic clearance in basic conditions as well as endogenous suppression of glucose production at moderate hyperglycaemia when compared to young ones can be observed. An increase in insulin resistance of the adipose tissue, skeletal muscles and liver, and subsequently the risk of diabetes development can be significantly limited by preventing the growth of adipose tissue by, among others, increasing physical activity and lowering energy load in the diet [40]. Studies confirmed the importance of visceral adipose tissue content in the intensification of insulin resistance in women aged $50-70$ years when compared to younger ones (18-35) [37]. Even a moderate growth of abdominal obesity with the coexisting dyslipidaemia in elderly people can favour insulin resistance [37].

Many authors underline the beneficial influence of physical training on the improvement of glucose tolerance and prevention of type 2 diabetes development in examined patients at any age $[43,44]$. Lowering insulin secretion during physical exercise is attributed to an increase in sympathetic impulsation and a decrease in parasympathetic one as well as an increase in nonesterified fatty acids utilisation [45]. It has also been found out that physical activity of low intensity increases the affinity of the receptor to insulin and lowers its number when fasting. Physical training also causes an increase in the expression and translocation as well as biosynthesis of new GLUT-4 transporters [46].

Many randomized controlled trials have measured the effect of physical activity alone or combined with dietary interventions on postmenopausal women's body weight or composition of the body. Evidence from the studies indicates that women should exercise and eat a caloric restricted diet to prevent weight gain during the menopause transition stage [47].

The present studies demonstrated that the program of physical activity is beneficial in terms of improvement of the plasma lipid profile as well as glycaemia and can be recommended in prophylactic and therapeutic goals. Finally, further research should focus on more rigorous study protocol including combined effect of physical ac- tivity and a caloric restricted diet, and a minimal time necessary to achieve a body composition defined by women and their health care professionals as healthy. These results would be more helpful for women and their health care professionals to choose an effective training program and dietary interventions.

\section{Conclusions}

The 12-week program of physical activity with the intensity of $60 \%$ of $\mathrm{HR}_{\max }$ without changes in dietary habits contributed to improving the plasma lipid profile and increased insulin sensitivity.

The proposed physical activity program without dietary intervention did not change the indices of body composition.

It is recommended to associate physical activity with a balanced diet, which probably will have a favourable impact on body composition.

Additional application of a properly balanced diet of low energy load to the program of physical activity could provide better results in improving lipids and carbohydrates metabolism and result in positive changes of body composition.

\section{Disclosure}

Authors report no conflict of interest.

\section{References}

1. O'Donell MJ, Xavier D, Liu L, et al. Risk factors for ischaemic and intracerebral hemorrhagic stroke in 22 countries (the INTERSTROKE study): a case-control study. Lancet 2010; 376: 112-123.

2. Bandosz P, O'Flaherty M, Drygas W. Decline in mortality from coronary heart disease in Poland after socioeconomic transformation: modeling study. BMJ 2012; 344: d8136.

3. Broda G, Rywik S. Multicenter national Polish population health status test-WOBASZ project with defined problems and treatment goals. Kardiol Pol 2005; 63: 601-604

4. Błędowski P, Mossakowska M, Chudek J, et al. Medical, psychological and socioeconomic aspects of aging in Poland: Assumption and objec tives of the PolSenior Project. Exp Gerontol 2011; 46: 1003-1009.

5. Zdrojewski T, Bandosz P, Szpakowski P, et al. Prevalence of main risk factors of cardiovascular diseases in Poland. Results of NATPOL PLUS test. Kardiol Pol 2004; 61: 546-558.

6. Drygas W, Jegier A. Physical activity in prophylaxis of heart and vascular diseases. W: Kardiologia zapobiegawcza II. Wydawnictwo MKa, Warszawa 2007; 43-449.

7. Czarkowska-Pączek B, Przybylski J. Energy processes taking place in the body during physical effort. In: An outline of physical effort. A textbook for students. Urban \& Partner, Wrocław 2006; 13-22.

8. Kelley G, Kelley K. Aerobic exercise and HDL-C: a meta-analysis of randomized controlled trials. Atherosclerosis 2006; 184: 207-215.

9. Pereira A, Huddleston D, Brickman A. An in vivo correlate of exerciseinduced neurogenesis in the adult dentate gyrus. Proc Natl Acad Sci USA 2007; 104: 5638-5643.

10. Drygas W, Jegier A. Recommendations concerning physical activity in prophylaxis of cardiovascular system. Czynniki Ryzyka 2003; 4: 76-84.

11. Drygas W, Jegier A. Physical activity in prophylaxis of heart and vascular diseases. Kardiologia zapobiegawcza II. Wydawnictwo MKa, Warszawa 2007; 443-461. 
12. Gibala M, Little J, MacDonald J, Hawley J. Physiological adaptations to low-volume, high-intensity interval training in health and disease. J Physiol 2012; 590: 1077-1084.

13. Biernat E, Stupnicki R, Gajewski A. International Physical Activity Ques tionnaire (IPAQ) - Polish version. Wychow Fiz Sport 2007; 51: 47-54.

14. Robergs R, Roberts S. Fundamental Principles of Exercise Physiology: For Fitness, Performance and Health. McGraw-Hill, Boston 2000

15. ACSM's Guidelines for Exercise Testing and Prescription. American College of Sports Medicine. Whaley M, Brubaker P, Otto R (eds.). Lippincott Williams \& Wilkins, Baltimore 2006.

16. Friedewald W, Lewy R, Fredrickson D. Estimation of the concentration of low-density lipoprotein cholesterol in plasma, without use of the pre parative ultracentrifuge. Clin Chem 1972; 18: 499-502.

17. Dobiasova M, Frohlich J. The plasma parameter log (TG/HDL-C) as atherogenc index: correlation with lipoprotein particle size and esterification rate in $\beta$-lipoprotein-depleted plasma (FER HDL). Clin Biochem 2001; 34: 583-588

18. Luc G, Bard J, Ferrieres J, et al. Value of HDL-cholesterol apolipoprotein A-1, lipoprotein A-1 and lipoprotein Al/All in prediction of coronary heart disease: the PRIME study. Prospective Epidemiological Study of Myocardial Infarction. Arterioscler Thromb Vasc Biol 2002; 22: 1155 1161.

19. Kunachowicz H, Nadolna L, Przygoda B, Iwanow K. Tables of nutritional values of foodstuffs. Prace IŻiż, Warszawa 1998

20. Jarosz M. Nutrition norms for Polish population - amendment. Prace IŻiż, Warszawa 2012

21. Bosy-Westphal A, Müller M. Identification of skeletal muscle mass depletion across age and $\mathrm{BMI}$ groups in health and disease - there is need for a unified definition. Int J Obes (Lond) 2015; 39: 379-386.

22. Bemben M, Massey B, Bemben D, et al. Age-related patterns in body composition for men aged 20-79-yr. Med Sci Sports Exerc 1995; 2 264-269.

23. Utzschneider K, Carr D, Hull R, et al. Impact of intra-abdominal fat and age on insulin sensitivity and beta-cell function. Diabetes 2004; 53 2867-2872.

24. Gutin B, Barbeau P, Owens S, et al. Effects of exercise intensity on cardiovascular fitness, total body composition and visceral adiposity of obese adolescents. J Clin Nutr 2002; 75: 818-826.

25. Hansen D, Dendale P, Berger J, et al. The effects of exercise training on fat-mass loss in obese patients during energy intake restriction. Sports Med 2007; 37: 31-46.

26. Asikainen TM, Miilunpalo S, Kukkonen-Harjula K, et al. Walking trials in postmenopausal women: effect of low doses of exercise and exercise fractionization on coronary risk factors. Scand J Med Sci Sports 2003; 13: 284-292

27. Asikainen T, Kukkonen-Harjula K, Miilunpalo S. Exercise for health for early postmenopausal women: a systematic review of randomized controlled trial. Sports Med 2004; 34: 753-778.

28. Murphy M, Nevill A, Mourtagh E, Holder R. The effects of walking on fitness, fatness and resting blood pressure: a meta-analysis of rand omized, controlled trial. Prev Med 2007; 44: 377-385.

29. Kukkonen-Harjula K, Hiilloskorpi H, Mänttäri A, et al. Self-guided brisk walking training with or without poles: a randomized-controlled trial in middle-aged women. Skand J Med Sci Sports 2007; 17: 316-323.
30. Kłosiewicz-Latoszek L, Szostak W, Podolec P, et al. Polish Forum for Prevention Guidelines on Diet. Kardiol Pol 2008; 66: 812-814.

31. Rybicki J, Leszczyńska-Bolewska B, Grochulska W, et al. Oxygen uptake during Nordic walking training in patients rehabilitated after coronary events. Kardiol Pol 2015; 73: 17-23.

32. Piotrowska S, Majchrzycki M. Physical exercise of women after menopause. Prz Menopauzalny 2013; 4: 347-351

33. Latosik E, Zubrzycki I, Ossowski Z, et al. Physiological responses associated with Nordic-walking training in systolic hypertensive postmenopausal women. J Hum Kinet 2014; 43: 185-190.

34. Kawamoto R, Kohara K, Katoh T, et al. Changes in oxidized low-density lipoprotein cholesterol are associated with changes in handgrip strength in Japanese community-dwelling persons. Endocrine 2015; 48: 871-877.

35. Ryan A, Ge S, Blumenthal J, et al. Aerobic exercise and weight loss reduce vascular markers of inflammation and improve insulin sensitivity in obese women. J Am Geriatr Soc 2014; 62: 607-614.

36. Santos-Gallego C, Badimon J. High-density lipoprotein and cardiovascular risk reduction: promises and realities. Rev Esp Cardiol 2012; 65: 305-308.

37. Chapman M. Therapeutic elevation of HDL-cholesterol to prevent atherosclerosis and coronary heart disease. Pharmacology \& Therapeutics 2006; 111: 893-908

38. Mineo C, Yuhanna I, Quon M, Shaul P. High density lipoprotein-induced endothelial nitric-oxide synthase activation is mediated by Akt and MAP kinases. J Biol Chem 2003; 278: 9142-9149.

39. Cromwell W. High-density lipoprotein associations with coronary heart disease: does measurement of cholesterol content give the best result? J Clin Lipidol 2007; 1: 57-64.

40. Barter P. Is high-density lipoprotein the protector of the cardiovascular system? Eur Heart J Suppl 2004; 6: A19-A22.

41. Kuliszkiewicz-Janus M, Mohamed A, Abod N. Biologia lipoproteiny HDL i jej przeciwmiażdżycowe działanie. Postepy Hig Med Dosw 2006; 60: 307-315.

42. Branth S, Sjodin A, Forslund A, et al. Minor changes in blood lipids after 6 weeks of high-volume low-intensity physical activity with strict energy balance control. Eur J Appl Physiol 2006; 96: 315-321.

43. Bogdański P, Pupek-Musialik D, Hen K, et al. Assessment of the influence of a 6-month-long physical activity on the level of insulin-sensitivity in obese women with metabolic syndrome. Geriatria Pol 2008; 2: 116-120.

44. Lumini J, Magalhaes J, Oliveira P, Ascensao A. Beneficial effects of exercise on muscle mitochondrial function in diabetes mellitus. Sports Med 2008; 38: 735-750

45. Goodpaster B, Katsiaras A, Kelley D. Enhanced fat oxidation through physical activity is associated with improvements in insulin sensitivity in obesity. Diabetes 2003; 52: 2191-2197.

46. Holten M, Zacho M, Gaster M, et al. Strenght training increases insulin-mediated glucose uptake GLUT-4 content and insulin signalling in skeletal muscle in patients with type 2 diabetes. Diabetes 2004; 53: 294-305.

47. Jull J, Stacey D, Beach S, et al. Lifestyle interventions targeting body weight changes during the menopause transition: a systematic review. J Obes 2014; 2014: 824310 